La revue La revue pour l'histoire du CNRS

POUR L'HISTOIRE DU CNRS

$2 \mid 2000$

Les premiers laboratoires du CNRS

\title{
Survivre à la science. Une certaine idée du futur
}

Jean-Jacques Salomon, Albin Michel, Paris, 1999

André Kaspi

\section{(2) OpenEdition}

\section{Journals}

Édition électronique

URL : https://journals.openedition.org/histoire-cnrs/376

DOI : 10.4000/histoire-cnrs.376

ISSN : 1955-2408

Éditeur

CNRS Éditions

Édition imprimée

Date de publication : 5 mai 2000

ISBN : 978-2-271-05708-2

ISSN : $1298-9800$

Référence électronique

André Kaspi, « Survivre à la science. Une certaine idée du futur », La revue pour l'histoire du CNRS [En ligne], 2 | 2000, mis en ligne le 07 mars 2006, consulté le 20 mai 2021. URL : http://

journals.openedition.org/histoire-cnrs/376; DOI : https://doi.org/10.4000/histoire-cnrs.376

Ce document a été généré automatiquement le 20 mai 2021

Comité pour l'histoire du CNRS 


\section{Survivre à la science. Une certaine idée du futur}

Jean-Jacques Salomon, Albin Michel, Paris, 1999

André Kaspi

1 Les temps incitent au bilan. Jean-Jacques Salomon dresse l'état des lieux et, parallèlement, réfléchit sur nos lendemains. Il part d'une observation à la fois simple et effrayante: la science remplace aujourd'hui la religion, sans parvenir à donner à l'homme les satisfactions spirituelles qu'il attend. La science tente de tout expliquer et, pourtant, elle nous laisse sur notre faim. Elle crée au moins autant de problèmes qu'elle voudrait en résoudre, autant d'inquiétudes que celles qu'elle ambitionne de dissiper, autant de frustrations qu'elle en surmonte.

2 Jean-Jacques Salomon fait une démonstration point par point. Le nucléaire a surgi dans notre monde et dans nos esprits le 6 août 1945, lorsque la première bombe atomique a anéanti la ville de Hiroshima. Désormais, nous avons vécu avec cette menace permanente, au milieu d'une course ininterrompue aux armements. Le multimédia qui nous fascine et fait naître le cybermonde, suscite dans le même temps la civilisation de l'éphémère et du virtuel. On pourrait ajouter, à la manière de Paul Virillo, qu'il fait peser sur nous le risque de la grande panne, du bogue généralisé auquel nous avons pourtant échappé dans les semaines passées. Que dire de la biologie, dont les découvertes nous poussent à la fois vers l'optimiste et le pessimisme. La médecine a chaussé ses bottes de sept lieues, mais le clonage nous guette, les organismes génétiquement modifiés sont sur le point de nous envahir, les manipulations de toutes sortes sont possibles, la maladie des « vaches folles » commence à exercer ses effets. Et l'affaire du sang contaminé, et la nouvelle donne de l'emploi, et le développement prétendument durable... On n'en finirait pas d'allonger la liste des bienfaits qui rendent notre vie plus facile et plus longue, et des périls qui la rendent plus hasardeuse et plus angoissante.

3 Alors, que faire? Jean-Jacques Salomon rappelle que d'autres époques ont connu des bouleversements d'une ampleur comparable. Au XVI ${ }^{\mathrm{e}}$ siècle, par exemple, Gutenberg fut une sorte de Bill Gates. Avant comme après, des massacres en tout genre, des 
guerres terriblement meurtrières, des chambardements dus à la science et à la technologie ont fait trembler sur leurs bases les sociétés et l'humanité tout entière. Nous ne sommes pas les premiers à redouter le pire tout en jouissant du meilleur. L'histoire relativise notre expérience. Les mondes nouveaux n'ont pas cessé de succéder les uns aux autres. Il serait, en conséquence, erroné de conclure que les chocs que nous subissons n'ont jamais eu de précédents. La science n'est pas une religion. Nous ne sommes pas des hommes soudainement métamorphosés en dieux. L'idéologie du progrès continu, bienfaisant, irréversible ne résiste pas à l'analyse. Jean-Jacques Salomon ne croit pas dans la « fin de l'histoire » à la manière de Francis Fukuyama. Il a bien raison. Il plaide pour une nouvelle Renaissance, marquée par la tolérance, l'humanisme et le principe de précaution. Pourquoi pas? Il faut pourtant observer que le remède semble bien insuffisant, si l'on garde à l'esprit le mal dans toute son ampleur, dans sa complexité et ses mutations. C'est sans doute cette inadéquation qui explique le regain de vigueur des croyances, des sectes et des religions. André Malraux prédisait que le $\mathrm{XXI}^{\mathrm{e}}$ siècle serait avant tout religieux. Il sera sans doute d'autant plus religieux que la science et la technologie le marqueront de leur empreinte. Voilà un parallélisme qui mériterait des investigations supplémentaires et ô combien instructives.

Les temps incitent au bilan. Jean-Jacques Salomon dresse l'état des lieux et, parallèlement, réfléchit sur nos lendemains. Il part d'une observation à la fois simple et effrayante: la science remplace aujourd'hui la religion, sans parvenir à donner à l'homme les satisfactions spirituelles qu'il attend. La science tente de tout expliquer et, pourtant, elle nous laisse sur notre faim. Elle crée au moins autant de problèmes qu'elle voudrait en résoudre, autant d'inquiétudes que celles qu'elle ambitionne de dissiper, autant de frustrations qu'elle en surmonte.

\section{AUTEUR}

\section{ANDRÉ KASPI}

Professeur à la Sorbonne 